\title{
Genetic polymorphisms in the renin-angiotensin system and cognitive decline in Parkinson's disease
}

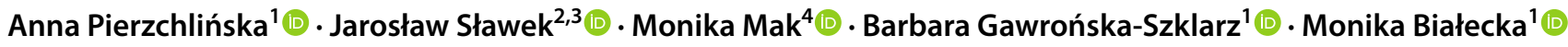

Received: 18 February 2021 / Accepted: 14 July 2021 / Published online: 23 July 2021

(c) The Author(s) 2021

\begin{abstract}
Background Renin-angiotensin system (RAS) influences the central nervous system not only through its peripheral impactthe brain possesses its own local RAS. Studies showed altered RAS components in Parkinson's disease (PD) and their association with oxidative stress which may be linked to neurodegeneration and dementia. Moreover, the protective functions of RAS blockade antagonists against cognitive decline and dementia have been suggested. This study aimed to examine whether genetic variability in RAS genes correlates with cognitive decline in PD.

Methods and results We genotyped single nucleotide polymorphisms (SNPs) in angiotensinogen (AGT: rs699, rs4762), angiotensin II receptors (AGTR1: rs5186 and AGTR2: rs5194, rs1403543) genes, as well as insertion/deletion polymorphism in the angiotensin-converting enzyme (ACE I/D) gene in 256 PD patients, divided into three groups: without cognitive decline, with mild cognitive impairment and with PD dementia. We did not find any significant differences in the frequencies of the analysed polymorphisms in any of the groups.

Conclusions Despite no direct correlation between the investigated polymorphisms in RAS genes and cognitive decline in $\mathrm{PD}$, we believe the impact of those genotypes may be indirect, affecting RAS blockade treatment.
\end{abstract}

Keywords Parkinson's disease $\cdot$ Renin-angiotensin system $\cdot$ Dementia $\cdot$ Cognitive decline $\cdot$ Genetic polymorphisms

\section{Introduction}

The impact of the renin-angiotensin system (RAS) on the central nervous system was originally considered by its influence on blood pressure and water and electrolyte balance since RAS components do not cross the blood-brain barrier [1]. Angiotensin-converting enzyme (ACE) forms the main effector peptide of RAS—angiotensin II (AII), which acts via two receptors: AT1 (AT1R) or AT2 (AT2R) [2].

Anna Pierzchlińska

anna.pierzchlinska@pum.edu.pl

1 Department of Pharmacokinetics and Therapeutic Drug Monitoring, Pomeranian Medical University, Powstańców Wlkp 72, 70-111 Szczecin, Poland

2 Department of Neurological-Psychiatric Nursing, Faculty of Health Sciences, Medical University of Gdansk, Gdansk, Poland

3 Department of Neurology, St Adalbert Hospital, Gdansk, Poland

4 Department of Health Psychology, Pomeranian Medical University, Szczecin, Poland
Further research confirmed that RAS exists also locally in many tissues, including the brain where astrocytes produce the precursor peptide to AII - angiotensinogen [3, 4].

Some components of RAS have been found to be altered in Parkinson's disease (PD) patients: ACE activity was increased in the cerebrospinal fluid and AT1R expression was decreased in the brain in a post-mortem study, which was associated with the loss of dopaminergic neurons [5, 6]. Villar-Cheda et al. [2] presented a correlation between AT1R expression levels and dopamine levels in rodents-the expression was higher in D1 or D2 dopamine receptor-deficient mice than in the controls. Angiotensin II activates the NADPH oxidase complex via AT1R which leads to reactive oxygen species (ROS) generation, causing oxidative stress and cell apoptosis as a consequence, including dopaminergic neurons $[7,8]$. The induction of parkinsonian symptoms was observed in PD animal models by the use of a neurotoxin that increased NADPH expression and microglia activation; moreover, increased expression of NADPH:quinone oxidoreductase was observed in the substantia nigra pars compacta of PD patients, among whom many were described as having dementia [8,9]. In the in vitro studies, ROS formation was 
diminished by AT1R antagonists or NADPH oxidase inhibitor [7]. However, AT2R antagonists acted in the opposite way and AT2R agonists exerted neuroprotective functions [10].

Therapy with ACE inhibitors (i.e. captopril, perindopril) exerted neuroprotective effects in a PD animal model; moreover, PD patients on perindopril reacted faster on their levodopa (L-dopa) medication, had reduced dyskinesia, and were more active during the day $[11,12]$. Several studies showed protective functions of RAS blockade-by ACE inhibitors or AT1R antagonists-against cognitive decline and dementia (in non-PD patients), or the progression of PD [13-15]. The severity of PD has been correlated with dementia [16, 17], thus slowing the progression of motor symptoms may be a protective factor against cognitive decline.

The prevalence of dementia in Parkinson's disease (PDD) is very high, as it can affect up to $80 \%$ after 12 years, significantly decreasing patients' quality of life and leading to their disability [18]. The aetiology of cognitive decline in PD is unclear and multifactorial; some susceptibility factors have been established: e.g. higher age, fewer years of education, longer disease duration, higher age-at-onset, higher L-dopa dose, more severe autonomic and depressive symptoms, as well as genetic susceptibility factors [16, 19]. The impact of the genetic variability in RAS on PD has been analysed [20]; however, no studies on its influence on cognitive decline in PD have been performed.

The aim of the presented research was to establish the impact of several polymorphisms in RAS - in the genes of angiotensinogen, ACE, AT1R, and AT2R-on the risk of mild cognitive impairment (MCI) or dementia in PD.

\section{Methods}

\section{Subjects}

The study population comprised of 256 patients of Caucasian origin (116 males and 140 females), aged from 35 to 89 (64.5 \pm 10.0 ), from two urban centres in Poland (Gdansk, Szczecin). The subjects were diagnosed with idiopathic PD according to UK Parkinson's Disease Society Brain Bank clinical diagnostic criteria [21]. All patients with clinical symptoms suggesting secondary causes of the parkinsonian syndrome (vascular, drug-induced), with features suggestive of atypical parkinsonian syndromes (multiple system atrophy, progressive supranuclear palsy and corticobasal syndrome) or with the presence of cardiovascular disease (e.g. stroke, heart failure) were excluded from final data analysis. Informed written consent was obtained before participation. The protocol of the study was approved by the relevant local ethics committee.
Based on the neuropsychological assessment described below, the group was divided into three subgroups: PD patients without MCI or dementia (PD-non cognitive impairment, PD-NCI, $\mathrm{n}=68$ ), PD patients with MCI (PD$\mathrm{MCI}=122$ ), and PD patients with dementia (PDD, $n=66$ ). Demographic and clinical data were collected according to a semi-structured interview and medical documentation and are presented in Table 1.

\section{Neurological examination}

Neurological examination was performed to confirm the PD diagnosis and exclude other symptoms suggesting atypical or symptomatic cases. It consisted of the Unified Parkinson's Disease Rating Scale (UPDRS; part II-IV), Hoehn-Yahr staging, and the Schwab-England activities of daily living scale. It was followed by magnetic resonance imaging to exclude other aetiologies.

\section{Neuropsychological assessment}

All assessments were conducted by an experienced psychologist, who established examination procedures and their standards before the onset of the study. Patients were examined in the 'on state'. The Mini-Mental State Examination (MMSE) test was used as a screening tool. Detailed neuropsychological examination, including the Wechsler Adult Intelligence Scale-Revised (WAIS-R), the Rey Auditory Verbal Learning Test (RAVLT), the Benton Visual Retention Test (BVRT), the Trail Making Test (TMT), the ReyOsterrieth Complex Figure Test (ROCF), the Verbal Fluency Test and the Wisconsin Card Sorting Test (WCST) was performed. The Beck Depression Inventory Test (BDI) was used to assess mood disturbances. In addition, all patients were examined by means of Parkinson's Disease-Cognitive Rating Scale (PDCRS). The diagnosis of dementia was established in accordance with Emre et al.'s criteria [22].

\section{Genetic study}

Peripheral venous blood samples were collected from each subject into tubes containing EDTA. Then extraction of genomic DNA using a Genomic Mini AX Blood SPIN was performed (A\&A Biotechnology, Poland). The concentration of every sample of DNA was measured spectrophotometrically by Nanodrop ND-1000 (Thermo Scientific, USA) and diluted to $20 \mathrm{ng} / \mathrm{ml}$. To determine polymorphisms in the genes of angiotensinogen (AGT: rs699, rs4762), AT1R (AGTR1: rs5186) and AT2R (AGTR2: rs5194, rs1403543) real-time PCR using pre-validated allelic discrimination TaqMan assays (rs699 assay ID: C_1985481_20, rs4762 assay ID: C_1985480_20, rs5186 assay ID: C_3187716_10, rs5194 assay ID: C_1841567_20, rs1403543 assay ID: 
Table 1 Demographic and clinical characteristics of PD patients without cognitive impairment (PD-NCI), with mild cognitive impairment (PD-MCI) and patients with Parkinson's disease dementia (PDD)

\begin{tabular}{|c|c|c|c|c|}
\hline Demographic and clinical data & $\begin{array}{l}\text { PD-NCI patients } \\
(\mathrm{n}=68)\end{array}$ & $\begin{array}{l}\text { PD-MCI patients } \\
(\mathrm{n}=122)\end{array}$ & $\begin{array}{l}\text { PDD patients } \\
(\mathrm{n}=66)\end{array}$ & $\mathrm{p}$ value \\
\hline Males/females & $42 / 26$ & $62 / 60$ & $36 / 30$ & $0.348^{\mathrm{a}}$ \\
\hline $\begin{array}{l}\text { Age [years] } \\
\text { mean, SD, range }\end{array}$ & $\begin{array}{l}63.3 \pm 10.6 \\
43-89 \\
(n=68)\end{array}$ & $\begin{array}{l}62.7 \pm 9.4 \\
39-87 \\
(n=122)\end{array}$ & $\begin{array}{l}69.0 \pm 9.1 \\
35-85 \\
(n=66)\end{array}$ & $<0.001^{\mathrm{b}}$ \\
\hline $\begin{array}{l}\text { Age at disease onset [years] } \\
\text { mean, SD, range }\end{array}$ & $\begin{array}{l}57.6 \pm 11.1 \\
37-87 \\
(n=68)\end{array}$ & $\begin{array}{l}56.4 \pm 11.0 \\
28-80 \\
(\mathrm{n}=122)\end{array}$ & $\begin{array}{l}60.3 \pm 10.5 \\
29-77 \\
(n=66)\end{array}$ & $0.017^{\mathrm{b}}$ \\
\hline $\begin{array}{l}\text { Disease duration [years] } \\
\text { mean, SD, range }\end{array}$ & $\begin{array}{l}5.7 \pm 4.4 \\
0.5-21 \\
(n=68)\end{array}$ & $\begin{array}{l}6.3 \pm 4.9 \\
1-21 \\
(n=122)\end{array}$ & $\begin{array}{l}8.6 \pm 5.9 \\
0.5-24 \\
(n=66)\end{array}$ & $0.034^{\mathrm{c}}$ \\
\hline $\begin{array}{l}\text { MMSE } \\
\text { mean, SD, range }\end{array}$ & $\begin{array}{l}28.8 \pm 1.4 \\
25-30 \\
(n=43)\end{array}$ & $\begin{array}{l}28.1 \pm 1.7 \\
24-30 \\
(n=118)\end{array}$ & $\begin{array}{l}23.5 \pm 4.3 \\
11-30 \\
(n=65)\end{array}$ & $<0.001^{\mathrm{c}}$ \\
\hline $\begin{array}{l}\text { UPDRS (part II-IV) score } \\
\text { mean, SD, range }\end{array}$ & $\begin{array}{l}24.5 \pm 11.5 \\
1-54 \\
(\mathrm{n}=59)\end{array}$ & $\begin{array}{l}30.7 \pm 15.7 \\
7-80 \\
(n=111)\end{array}$ & $\begin{array}{l}46.8 \pm 21.0 \\
6-101 \\
(n=61)\end{array}$ & $<0.001^{\mathrm{c}}$ \\
\hline Daily L-dopa dosage [mg] & $\begin{array}{l}606.2 \pm 337.6 \\
150-1750 \\
(n=63)\end{array}$ & $\begin{array}{l}722.8 \pm 447.5 \\
150-1900 \\
(n=118)\end{array}$ & $\begin{array}{l}820.9 \pm 436.5 \\
100-2000 \\
(n=64)\end{array}$ & $<0.001^{\mathrm{c}}$ \\
\hline
\end{tabular}

p values calculated by means of: ${ }^{a} \chi^{2}$ test; ${ }^{b}$ one-way parametric ANOVA test; ${ }^{c}$ one-way non-parametric ANOVA test (Kruskal-Wallis test)
C_7481825_10; Thermo Scientific, USA) was carried out. The insertion/deletion (I/D) polymorphism in the angiotensin-converting enzyme's gene $(A C E)$ was analysed by PCR with the second round of amplification for D homozygous carriers due to preferential amplification of D allele [23]. The genotypes of $A C E$ I/D were determined by running the products in $3 \%$ agarose gel with ethidium bromide $(1 \mu \mathrm{g} / \mathrm{mL})$ for UV visualization. The buffer used was $1 \mathrm{X}$ Tris-borateEDTA (TBE) buffer (Thermo Scientific, USA).

\section{Statistical analysis}

Concordance of genotypes distributions with Hardy-Weinberg equilibrium was assessed using the $\chi^{2}$ test (for X-linked gene-AGTR2-only in women). Genetic case-control analyses between study groups were performed using the $\chi^{2}$ test (between 3 groups) or Fisher exact test (between 2 groups). The minor alleles of single nucleotide polymorphisms were chosen according to the ALFA Allele Frequency database (https://www.ncbi.nlm. nih.gov/snp/docs/gsr/alfa/) for the European population, the minor allele of $A C E$ insertion/deletion was chosen according to the available literature. Odds ratios (OR) and $95 \%$ confidence intervals $(95 \% \mathrm{CI})$ were calculated using Wald's method with the continuity correction. The polymorphisms located on the X chromosome (AGTR2 rs5194 and rs 1403543) were also presented separately for men and women. For demographic and clinical data, the alignment with normal distribution was tested by means of the Shapiro-Wilk test, and further analyses were performed by means of a one-way parametric ANOVA test or oneway non-parametric ANOVA test (Kruskal-Wallis test). A p value of less than 0.05 was considered statistically significant. The analyses were performed in Statistica ver. 13.2 (TIBCO Software Inc., USA).

\section{Results}

The groups of PD-NCI, PD-MCI, and PDD did not differ in terms of sex, but varied significantly in the mean age of the participants, disease duration, age at disease onset, MMSE score, UPDRS score, and daily L-dopa dosage, with the greatest mean values for all of them in PDD group (Table 1).

The genotype distributions of all tested polymorphisms, except for $A C E$ I/D in PD-MCI group, were in Hardy-Weinberg equilibrium (Table 2). The number of $A C E$ heterozygous carriers in PD-MCI was expected to be lower $(n=60$, $50.0 \%$, while both the numbers of the homozygous carriers were expected to be higher (DD $n=28.5,23.75 \%$; II $\mathrm{n}=31.5,26.25 \%$ ), according to the $\chi^{2}$ test calculation.

The genotype and allele frequencies of any of the analysed polymorphisms did not vary significantly between the groups. The highest observed difference was noted for the minor allele of $A G T$ rs4762:C > T polymorphism; however, without statistical significance. Minor alleles, whose frequencies are reported to be around $50 \%$, in some cases, were more often observed than the major alleles, i.e. $A G T$ rs699:C in PD-NCI, AGTR2 rs5194:A in PD-MCI (men and 
Table 2 Frequencies of the studied polymorphisms in PD patients without cognitive impairment (PD-NCI), with mild cognitive impairment (PD-MCI) or patients with Parkinson's disease dementia (PDD)

\begin{tabular}{|c|c|c|c|c|c|}
\hline Polymorphism & Genotype/allele & PD-NCI n (\%) & PD-MCI n (\%) & PDD n (\%) & $\mathrm{p}$ value \\
\hline \multirow[t]{5}{*}{$A G T$ rs699: $\mathrm{T}>\mathrm{C}$} & $\mathrm{TT}$ & $15(22.1)$ & $33(27.3)$ & $20(30.8)$ & \multirow[t]{3}{*}{0.535} \\
\hline & $\mathrm{CT}$ & $33(48.5)$ & $63(52.1)$ & $28(43.1)$ & \\
\hline & $\mathrm{CC}$ & $20(29.4)$ & $25(20.7)$ & $17(26.1)$ & \\
\hline & $\mathrm{CT}+\mathrm{CC}$ & 53 & 88 & 45 & 0.518 \\
\hline & Minor allele (C) frequency & $(53.7)$ & $(46.7)$ & $(47.7)$ & 0.409 \\
\hline \multirow[t]{5}{*}{$A G T \mathrm{rs} 4762: \mathrm{C}>\mathrm{T}$} & $\mathrm{CC}$ & $45(66.2)$ & $86(71.1)$ & $51(78.5)$ & \multirow[t]{3}{*}{0.560} \\
\hline & $\mathrm{CT}$ & $20(29.4)$ & $32(26.4)$ & $13(20.0)$ & \\
\hline & TT & $3(4.4)$ & $3(2.5)$ & $1(1.5)$ & \\
\hline & $\mathrm{CT}+\mathrm{TT}$ & 23 & 35 & 14 & 0.285 \\
\hline & Minor allele $(\mathrm{T})$ frequency & $(19.1)$ & $(15.7)$ & $(11.5)$ & 0.233 \\
\hline \multirow[t]{5}{*}{ AGTR1 rs5186: $\mathrm{A}>\mathrm{C}$} & AA & $37(54.4)$ & $60(49.6)$ & $35(53.8)$ & \multirow[t]{3}{*}{0.886} \\
\hline & $\mathrm{AC}$ & $27(39.7)$ & $52(43.0)$ & $24(37.0)$ & \\
\hline & $\mathrm{CC}$ & $4(5.9)$ & $9(7.4)$ & $6(9.2)$ & \\
\hline & $\mathrm{AC}+\mathrm{CC}$ & 31 & 61 & 30 & 0.767 \\
\hline & Minor allele $(\mathrm{C})$ frequency & $(25.7)$ & $(29.0)$ & $(27.7)$ & 0.802 \\
\hline \multirow[t]{3}{*}{ AGTR2 (X chr.) rs5194: $\mathrm{A}>\mathrm{G}$} & $\mathrm{G}$ & $47(50.5)$ & $81(45.3)$ & $46(49.5)$ & \multirow[t]{2}{*}{0.750} \\
\hline & A & $46(49.5)$ & $98(54.7)$ & $47(50.5)$ & \\
\hline & Minor allele (A) frequency & $(49.5)$ & $(54.7)$ & $(50.5)$ & 0.750 \\
\hline \multirow{3}{*}{$\begin{array}{l}\text { AGTR2 (X chr.) rs5194:A > G } \\
\text { only men }\end{array}$} & $\mathrm{G}$ & $21(51.2)$ & $30(49.2)$ & $20(57.1)$ & \multirow[t]{3}{*}{0.751} \\
\hline & A & $20(48.8)$ & $31(50.8)$ & $15(42.9)$ & \\
\hline & Minor allele (A) frequency & $(48.8)$ & $(50.8)$ & $(42.9)$ & \\
\hline \multirow{5}{*}{$\begin{array}{l}A G T R 2 \text { (X chr.) rs5194:A > G } \\
\text { only women }\end{array}$} & GG & $5(19.2)$ & $10(16.9)$ & $5(17.2)$ & \multirow[t]{3}{*}{0.884} \\
\hline & AG & $16(61.5)$ & $31(52.5)$ & $16(55.2)$ & \\
\hline & AA & $5(19.2)$ & $18(30.5)$ & $8(27.6)$ & \\
\hline & $\mathrm{AG}+\mathrm{AA}$ & 21 & 49 & 24 & 0.967 \\
\hline & Minor allele (A) frequency & $(50.0)$ & $(56.8)$ & $(55.2)$ & 0.714 \\
\hline \multirow[t]{3}{*}{ AGTR2 (X chr.) rs $1403543: \mathrm{G}>\mathrm{A}$} & A & $46(49.5)$ & $90(50.3)$ & $47(50.5)$ & \multirow[t]{2}{*}{0.988} \\
\hline & G & $47(50.5)$ & 89 (49.7) & $46(49.5)$ & \\
\hline & Minor allele $(G)$ frequency & $(50.5)$ & $(49.7)$ & $(49.5)$ & 0.988 \\
\hline \multirow{3}{*}{$\begin{array}{l}\text { AGTR2 (X chr.) rs } 1403543: \mathrm{G}>\mathrm{A} \\
\text { only men }\end{array}$} & A & $21(51.2)$ & $28(45.9)$ & $19(54.3)$ & \multirow[t]{3}{*}{0.710} \\
\hline & $\mathrm{G}$ & $20(48.8)$ & $33(54.1)$ & $16(45.7)$ & \\
\hline & Minor allele $(G)$ frequency & $(48.8)$ & $(54.1)$ & $(45.7)$ & \\
\hline \multirow{5}{*}{$\begin{array}{l}\text { AGTR2 (X chr.) rs } 1403543: \mathrm{G}>\mathrm{A} \\
\text { only women }\end{array}$} & AA & $5(19.2)$ & $16(27.1)$ & $6(20.7)$ & \multirow[t]{3}{*}{0.933} \\
\hline & AG & $15(57.7)$ & $30(50.8)$ & $16(55.2)$ & \\
\hline & GG & $6(23.1)$ & $13(22.0)$ & $7(24.1)$ & \\
\hline & $\mathrm{AG}+\mathrm{GG}$ & 21 & 43 & 23 & 0.666 \\
\hline & Minor allele $(\mathrm{G})$ frequency & $(51.9)$ & $(47.5)$ & $(51.7)$ & 0.805 \\
\hline \multirow[t]{5}{*}{$A C E \mathrm{I} / \mathrm{D}$} & $\mathrm{DD}$ & $9(13.4)$ & $21(17.5)^{\mathrm{a}}$ & $10(15.4)$ & \multirow[t]{3}{*}{0.662} \\
\hline & ID & $39(58.2)$ & $75(62.5)^{\mathrm{a}}$ & $37(56.9)$ & \\
\hline & II & $19(28.4)$ & $24(20.0)^{\mathrm{a}}$ & $18(27.7)$ & \\
\hline & $\mathrm{ID}+\mathrm{II}$ & 58 & 99 & 55 & 0.760 \\
\hline & Minor allele (I) frequency & $(57.5)$ & $(51.3)$ & $(56.2)$ & 0.446 \\
\hline
\end{tabular}

$\mathrm{p}$ values for alleles and genotypes calculated by means of $\chi^{2}$ test in relation to major allele or homozygotes for a major allele ${ }^{a}$ the genotype distribution not in Hardy-Weinberg equilibrium

women) and PDD (women), AGTR2 rs 1403543:G in PDMCI (men), PD-NCI (women), PDD (women), $A C E$ I/D in all three groups.
The comparisons of the genotypes and alleles distributions between the groups: (1) PD-NCI vs. PD-MCI + PDD, (2) PD-NCI + PD-MCI vs. PDD, (3) PD-NCI vs. PD-MCI, 
or (4) PD-NCI vs. PDD did not reveal any significant differences (Supplementary Table 1).

\section{Discussion}

We have found that none of the analysed polymorphisms in the genes of renin-angiotensin system, i.e. rs699, rs 4762 in $A G T$, rs5186 in AGTR1, rs5194, rs 1403543 in AGTR2 or $A C E$ I/D was associated with MCI or dementia in Parkinson's disease.

Up to date, no study has investigated the correlation between the genetic variability in RAS genes and cognitive impairment in PD. The most widely studied of the mentioned genetic variants in the context of PD or cognitive impairment was the $A C E \mathrm{I} / \mathrm{D}$ polymorphism which is responsible for a significant variance in ACE levels-the DD genotype results in two-fold higher plasma and tissue ACE levels than in the II carriers [24]. Song and Lee [20] in their meta-analysis, including five studies on PD, did not find any association between the ACE I/D polymorphism and PD risk, and none of the included studies reported a correlation between ACE I/D and PD either. There was no information on the cognitive status of the participants. However, the analysis revealed an observation about the frequency of the polymorphism among different ethnic groups-in the control groups, PD group and schizophrenia group, D allele frequency was around 53\% in Europeans and Australians, but only 29\% in the Turkish population, and 34\% in Asians. Huo et al. [25] did not find an impact of ACE I/D polymorphism on the occurrence of PD either (Asian population). Since ACE activity was elevated in the cerebrospinal fluid of PD patients longitudinally treated with L-dopa [5], the polymorphism was analysed in association with the side effects of the drug. The studies did not find a correlation with dyskinesia or fluctuations [26, 27], but Lin et al. [26] reported higher risk of L-dopa-induced psychosis among II homozygotes (OR 2.542, 95\% CI 0.034-0.242, $\mathrm{p}=0.012$ ).

The impact of RAS genes variability on dementia, Alzheimer's disease (AD) and vascular dementia was analysed in two Swedish studies [28, 29]. One of them reported a two-fold higher risk of dementia in ACE II homozygotes compared to combined ID and DD genotypes (OR 2.17; 95\% CI 1.22-3.85; $\mathrm{p}=0.008)$; moreover, II carriers were more likely to develop dementia under the age of 70 (OR 4.35; 95\% CI 1.37-13.86; $\mathrm{p}=0.013$ ) [28]. In a subsequent study, the authors revealed no correlation between the ACE I/D polymorphism and dementia during the follow-up, likewise with AGTR1 rs5186, whose CC genotype was associated with dementia only at baseline (OR 3.25; 95\% CI 1.42-7.06; $\mathrm{p}=0.001$ ) [29]. Unfortunately, the results were not presented for $\mathrm{AD}$ and vascular dementia separately. There was also no information about the inclusion of PDD in the analysis.
Dementia is a complex term, with various pathogenesis and clinical presentation, thus susceptibility factors, including genetic polymorphisms, may lack resemblance in different types of dementia. Such an example is a variant of the apolipoprotein E gene-APOE4-which is an established risk factor for AD; whereas, studies on PDD showed conflicting results [30].

We assume that polymorphisms in RAS genes may exert an indirect influence on cognitive decline in PD. Some studies revealed a correlation between white matter hyperintensities (WMH) seen in magnetic resonance imaging with dementia in PD [31-33]. Taylor et al. [34] analysed polymorphisms in both angiotensin II receptors genes: A1166C (rs5186) in AGTR1 and C3123A (rs2148582) in AGTR2. Although no correlation was found between the polymorphisms and WMH in women, WMH volume changed less in male 1166A homozygotes compared to other A1166C genotypes. The authors also showed a protective impact of AGTR2 3123C allele against WMH volume change in hypertensive men. However, the results were not supported by Gebril et al. [35], as they found no association between AGTR1 A1166C and WMH development in the aging brain. A polymorphism in $A G T$ gene (rs699) was reported to correlate not only with the white matter integrity, but also with cognition in healthy adults-mutant TT homozygotes performed worse in tests assessing attention, processing speed and language functions [36].

Another indirect influence of RAS genes variability on cognitive functions, also in PD patients, may be that it alters the neuroprotective benefits of ACE inhibitors. Hajjar et al. conducted a study with 8-year's follow-up on 3000 cognitively intact elderly participants-Caucasians and African American, of whom 15\% were treated with ACE inhibitors [37]. They found that the medication was protective against cognitive decline in AA carriers of AGT 6AG (rs5051), and in CC homozygotes of the AGT M235T (rs699) polymorphism, both associated with higher angiotensinogen levels. Therefore, only in those carriers the inhibitors may show neuroprotective effect by decreasing RAS activity. The association was significant only in Caucasians; moreover, no impact of the $A C E \mathrm{I} / \mathrm{D}$ polymorphism was found in either group.

We describe here the classical RAS pathway and polymorphisms within its genes. A rising number of publications has focused on the alternative axis, i.e., angiotensin converting enzyme 2 (ACE2), angiotensin (1-7) [Ang-(1-7)] produced by ACE2 from AII, and Mas receptor. Activating the ACE2/ Ang-(1-7)/Mas axis in animal models resulted in neuroprotective benefits, opposed to the detrimental effects of the ACE/ AII/AT1R pathway [38, 39]. Although a preliminary genetic analysis in neurodegenerative diseases showed no significant expression changes in human subjects [40], some alterations in Ang-(1-7) or ACE2 protein levels in $\mathrm{AD}$ and $\mathrm{PD}$ have been 
revealed. Ang-(1-7) plasma levels were decreased in both PD and $\mathrm{AD}$ patients compared to the controls [41-43]. Moreover, the plasma concentration of Ang-(1-7) positively correlated with cognitive functions in AD [42]. The analyses on ACE2 showed contradictory results $[41,44,45]$, and no studies on Mas levels have been performed. The available data is scarce, thus analysing genetic variability in Ang-(1-7)/ACE2/Mas axis in terms of PD susceptibility, or cognitive decline in PD, could shed some light on the possible neuroprotection exerted by this pathway. Moreover, ACE2 is highly expressed in the substantia nigra and serves as a cellular doorway for the SARS-CoV-2 virus [46]. Some cases of parkinsonism following COVID-19 have been reported [47]. What is the nature of this correlation, as well as whether the SARS-CoV-2 infection may result in a fully developed PD, is still unknown.

We are obliged to indicate some limitations in our study. First of all, the prevalence of dementia in PD increases with age, thus it is possible that in the follow-up, MCI or dementia could affect more participants who were cognitively intact at the baseline. The next step was to assess potential risk factors in patients whose cognitive function had deteriorated. A disadvantage of our study may be the fact that the groups were not matched according to co-morbidities like arterial hypertension, diabetes mellitus, dyslipidaemia, and other vascular risk factors that could influence the diagnosis of cognitive decline.

Another issue may be the distribution of the ACE I/D polymorphism in the PD-MCI group, which was not in Hardy-Weinberg equilibrium. This could have resulted from genotyping errors, as the method used (PCR with subsequent electrophoresis) is less precise than real-time PCR. However, the numbers seemed to be equally affected in each of the genotypes, without tending towards any of the homozygotes, thus not indicating an analysis inaccuracy that would probably result in outnumbered DD heterozygotes. Allele and genotype frequencies of $A C E$ I/D between the groups did not differ significantly, not correlating with the cognitive phenotype. This deviation could disappear in a larger sample or in a group of participants from more than two centres.

Finally, it is also possible that the genetic variability in the material extracted from peripheral blood may be different in local tissues, i.e. in the brain, thus not reflecting the actual correlation between the polymorphisms in RAS genes and cognitive impairment.

Nevertheless, our study is the first to extensively analyse the genetic variation in RAS with regard to PD, cognitive decline and dementia.

\section{Conclusions}

In the presented analysis we did not find any association between genetic polymorphisms in RAS and mild cognitive impairment or dementia in Parkinson's disease patients.
However, the impact of RAS and the variability in its genes on cognitive decline in PD may be indirect, influencing the risk of cerebral hyperintensities or the impact of antihypertensive treatment with ACE inhibitors. The available research is scarce, not providing any answers to these hypotheses. Further work on the susceptibility factors for dementia in Parkinson's disease is needed.

Supplementary Information The online version contains supplementary material available at https://doi.org/10.1007/s11033-021-06569-6.

Author contributions Conceptualization: JS, MB; Methodology: JS, MB; Formal analysis and investigation: AP, JS, MM, MB; Writingoriginal draft preparation: AP; Writing — review and editing: JS, MB; Resources: BGS; Supervision: JS, MB.

Funding The research was funded by institutional grants of the Department of Pharmacokinetics and Therapeutic Drug Monitoring, Pomeranian Medical University, Szczecin, Poland (WLA-12901/S/16/2016-2020). No external funding was received.

Data availability The data that support the findings of this study, except for patients' identifiers, are available from the corresponding author upon reasonable request.

\section{Declarations}

Conflicts of interest The authors declare that they have no conflict of interest.

Ethical approval All procedures performed in studies involving human participants were in accordance with the ethical standards of the institutional research committee (The Bioethics Committee of the Pomeranian Medical University, KB-0012/151/15) and with the 1964 Helsinki declaration and its later amendments or comparable ethical standards.

Informed consent Informed consent was obtained from all individual participants included in the study.

Open Access This article is licensed under a Creative Commons Attribution 4.0 International License, which permits use, sharing, adaptation, distribution and reproduction in any medium or format, as long as you give appropriate credit to the original author(s) and the source, provide a link to the Creative Commons licence, and indicate if changes were made. The images or other third party material in this article are included in the article's Creative Commons licence, unless indicated otherwise in a credit line to the material. If material is not included in the article's Creative Commons licence and your intended use is not permitted by statutory regulation or exceeds the permitted use, you will need to obtain permission directly from the copyright holder. To view a copy of this licence, visit http://creativecommons.org/licenses/by/4.0/.

\section{References}

1. Jackson L, Eldahshan W, Fagan SC, Ergul A (2018) Within the brain: the renin angiotensin system. Int J Mol Sci 19:876. https:// doi.org/10.3390/ijms19030876 
2. Villar-Cheda B, Dominguez-Meijide A, Valenzuela R, Granado N, Moratalla R, Labandeira-Garcia JL (2014) Aging-related dysregulation of dopamine and angiotensin receptor interaction. Neurobiol Aging 35:1726-1738. https://doi.org/10.1016/j.neurobiola ging.2014.01.017

3. Deschepper CF, Bouhnik J, Ganong WF (1986) Colocalization of angiotensinogen and glial fibrillary acidic protein in astrocytes in rat brain. Brain Res 374:195-198. https://doi.org/10.1016/00068993(86)90411-7

4. Stornetta RL, Hawelu-Johnson CL, Guyenet PG, Lynch KR (1988) Astrocytes synthesize angiotensinogen in brain. Science 242:1444-1446. https://doi.org/10.1126/science.3201232

5. Konings CH, Kuiper MA, Bergmans PL, Grijpma AM, van Kamp GJ, Wolters EC (1994) Increased angiotensin-converting enzyme activity in cerebrospinal fluid of treated patients with Parkinson's disease. Clin Chim Acta 231:101-106. https://doi. org/10.1016/0009-8981(94)90259-3

6. Zawada WM, Mrak RE, Biedermann J, Palmer QD, Gentleman SM, Aboud O, Griffin WS (2015) Loss of angiotensin II receptor expression in dopamine neurons in Parkinson's disease correlates with pathological progression and is accompanied by increases in Nox4- and 8-OH guanosine-related nucleic acid oxidation and caspase- 3 activation. Acta Neuropathol Commun 3:9. https://doi.org/10.1186/s40478-015-0189-z

7. Rodriguez-Pallares J, Rey P, Parga JA, Muñoz A, Guerra MJ, Labandeira-Garcia JL (2008) Brain angiotensin enhances dopaminergic cell death via microglial activation and NADPHderived ROS. Neurobiol Dis 31:58-73. https://doi.org/10. 1016/j.nbd.2008.03.003

8. Mertens B, Vanderheyden P, Michotte Y, Sarre S (2010) The role of the central renin-angiotensin system in Parkinson's disease. J Renin Angiotensin Aldosterone Syst 11:49-56. https:// doi.org/10.1177/1470320309347789

9. van Muiswinkel FL, de Vos RA, Bol JG, Andringa G, Jansen Steur EN, Ross D, Siegel D, Drukarch B (2004) Expression of NAD(P)H:quinone oxidoreductase in the normal and Parkinsonian substantia nigra. Neurobiol Aging 25:1253-1262. https:// doi.org/10.1016/j.neurobiolaging.2003.12.010

10. Lu J, Wu L, Jiang T, Wang Y, Zhao H, Gao Q, Pan Y, Tian $Y$ et al (2015) Angiotensin AT2 receptor stimulation inhibits activation of NADPH oxidase and ameliorates oxidative stress in rotenone model of Parkinson's disease in CATH.a cells. Neurotoxicol Teratol 47:16-24. https://doi.org/10.1016/j.ntt.2014. 11.004

11. Reardon KA, Mendelsohn FA, Chai SY, Horne MK (2000) The angiotensin converting enzyme (ACE) inhibitor, perindopril, modifies the clinical features of Parkinson's disease. Aust N Z J Med 30:48-53. https://doi.org/10.1111/j.1445-5994.2000.tb010 54.x

12. Lopez-Real A, Rey P, Soto-Otero R, Mendez-Alvarez E, Labandeira-Garcia JL (2005) Angiotensin-converting enzyme inhibition reduces oxidative stress and protects dopaminergic neurons in a 6-hydroxydopamine rat model of Parkinsonism. J Neurosci Res 81:865-873. https://doi.org/10.1002/jnr.20598

13. Zhuang S, Wang HF, Li J, Wang HY, Wang X, Xing CM (2016) Renin-angiotensin system blockade use and risks of cognitive decline and dementia: a meta-analysis. Neurosci Lett 624:53-61. https://doi.org/10.1016/j.neulet.2016.05.003

14. Zhuang S, Wang HF, Wang X, Li J, Xing CM (2016) The association of renin-angiotensin system blockade use with the risks of cognitive impairment of aging and Alzheimer's disease: a metaanalysis. J Clin Neurosci 33:32-38. https://doi.org/10.1016/j.jocn. 2016.02.036

15. Udovin L, Otero-Losada M, Bordet S, Chevalier G, Quarracino C, Capani F, Pérez-Lloret S (2021) Effects of angiotensin type 1 receptor antagonists on Parkinson's disease progression: an exploratory study in the PPMI database. Parkinsonism Relat Disord 86:34-37. https://doi.org/10.1016/j.parkreldis.2021.03.007

16. Zhu K, van Hilten JJ, Marinus J (2014) Predictors of dementia in Parkinson's disease; findings from a 5-year prospective study using the SCOPA-COG. Parkinsonism Relat Disord 20:980-985. https://doi.org/10.1016/j.parkreldis.2014.06.006

17. Anang JB, Gagnon JF, Bertrand JA, Romenets SR, Latreille V, Panisset M, Montplaisir J, Postuma RB (2014) Predictors of dementia in Parkinson disease: a prospective cohort study. Neurology 83:1253-1260. https://doi.org/10.1212/WNL.0000000000 000842

18. Aarsland D, Andersen K, Larsen JP, Lolk A, Kragh-Sørensen P (2003) Prevalence and characteristics of dementia in Parkinson disease: an 8-year prospective study. Arch Neurol 60:387-392. https://doi.org/10.1001/archneur.60.3.387

19. Huertas I, Jesús S, García-Gómez FJ, Lojo JA, Bernal-Bernal I, Bonilla-Toribio M, Martín-Rodriguez JF, García-Solís D et al (2017) Genetic factors influencing frontostriatal dysfunction and the development of dementia in Parkinson's disease. PLoS ONE 12:e0175560. https://doi.org/10.1371/journal.pone.0175560

20. Song GG, Lee YH (2015) The insertion/deletion polymorphism in the angiotensin-converting enzyme and susceptibility to schizophrenia or Parkinson's disease: a meta-analysis. J Renin Angiotensin Aldosterone Syst 16:434-442. https://doi.org/10.1177/14703 20313495909

21. Hughes AJ, Daniel SE, Kilford L, Lees AJ (1992) Accuracy of clinical diagnosis of idiopathic Parkinson's disease: a clinicopathological study of 100 cases. J Neurol Neurosurg Psychiatry 55:181-184. https://doi.org/10.1136/jnnp.55.3.181

22. Emre M, Aarsland D, Brown R, Burn DJ, Duyckaerts C, Mizuno Y, Broe GA, Cummings J et al (2007) Clinical diagnostic criteria for dementia associated with Parkinson's disease. Mov Disord 22:1689-1707. https://doi.org/10.1002/mds.21507

23. Valdez-Haro A, Valle Y, Valdes-Alvarado E, Casillas-Muñoz F, Muñoz-Valle JF, Reynoso-Villalpando GL, Flores-Salinas HE, Padilla-Gutiérrez JR (2017) Assessment of the rs4340 ACE gene polymorphism in acute coronary syndrome in a Western Mexican population. Genet Mol Res. https://doi.org/10.4238/gmr16039779

24. Rigat B, Hubert C, Alhenc-Gelas F, Cambien F, Corvol P, Soubrier $\mathrm{F}$ (1990) An insertion/deletion polymorphism in the angiotensin I-converting enzyme gene accounting for half the variance of serum enzyme levels. J Clin Invest 86:1343-1346. https://doi. org/10.1172/JCI114844

25. Huo Z, Luo X, Zhan X, Chu Q, Xu Q, Yao J, Pang H (2017) Genetic analysis of indel markers in three loci associated with Parkinson's disease. PLoS ONE 12:e0184269. https://doi.org/10. 1371/journal.pone.0184269

26. Lin JJ, Yueh KC, Lin SZ, Harn HJ, Liu JT (2007) Genetic polymorphism of the angiotensin converting enzyme and L-dopainduced adverse effects in Parkinson's disease. J Neurol Sci 252:130-134. https://doi.org/10.1016/j.jns.2006.10.018

27. Pascale E, Purcaro C, Passarelli E, Guglielmi R, Vestri AR, Passarelli F, Meco G (2009) Genetic polymorphism of angiotensinconverting enzyme is not associated with the development of Parkinson's disease and of L-dopa-induced adverse effects. J Neurol Sci 276:18-21. https://doi.org/10.1016/j.jns.2008.08.017

28. Gustafson DR, Melchior L, Eriksson E, Sundh V, Blennow K, Skoog I (2010) The ACE insertion deletion polymorphism relates to dementia by metabolic phenotype, APOEepsilon4, and age of dementia onset. Neurobiol Aging 31:910-916. https://doi.org/10. 1016/j.neurobiolaging.2008.07.015

29. Zettergren A, Kern S, Gustafson D, Gudmundsson P, Sigström R, Östling S, Eriksson E, Zetterberg H et al (2017) The ACE gene is associated with late-life major depression and age at dementia onset in a population-based cohort. Am J Geriatr Psychiatry 25:170-177. https://doi.org/10.1016/j.jagp.2016.06.009 
30. Pierzchlińska A, Białecka M, Kurzawski M, Sławek J (2018) The impact of apolipoprotein $\mathrm{E}$ alleles on cognitive performance in patients with Parkinson's disease. Neurol Neurochir Pol 52:477482. https://doi.org/10.1016/j.pjnns.2018.04.003

31. Lee SJ, Kim JS, Yoo JY, Song IU, Kim BS, Jung SL, Yang DW, Kim YI et al (2010) Influence of white matter hyperintensities on the cognition of patients with Parkinson disease. Alzheimer Dis Assoc Disord 24:227-233. https://doi.org/10.1097/WAD.0b013 e3181d71a13

32. Sławek J, Roszmann A, Robowski P, Dubaniewicz M, Sitek EJ, Honczarenko K, Gorzkowska A, Budrewicz S et al (2013) The impact of MRI white matter hyperintensities on dementia in Parkinson's disease in relation to the homocysteine level and other vascular risk factors. Neurodegener Dis 12:1-12. https://doi.org/ $10.1159 / 000338610$

33. Nicoletti A, Luca A, Baschi R, Cicero CE, Mostile G, Davì M, La Bianca G, Restivo V, Zappia M, Monastero R (2021) Vascular risk factors, white matter lesions and cognitive impairment in Parkinson's disease: the PACOS longitudinal study. J Neurol 268:549-558. https://doi.org/10.1007/s00415-020-10189-8

34. Taylor WD, Zhao Z, Ashley-Koch A, Payne ME, Steffens DC, Krishnan RR, Hauser E, MacFall JR (2013) Fiber tract-specific white matter lesion severity findings in late-life depression and by AGTR1 A1166C genotype. Hum Brain Mapp 34:295-303. https:// doi.org/10.1002/hbm.21445

35. Gebril OH, Kirby J, Savva G, Brayne C, Ince PG (2011) HFE H63D, C282Y and AGTR1 A1166C polymorphisms and brain white matter lesions in the aging brain. J Neurogenet 25:7-14. https://doi.org/10.3109/01677063.2011.556206

36. Salminen LE, Schofield PR, Pierce KD, Zhao Y, Luo X, Wang Y, Laidlaw DH, Cabeen RP, Conturo TE, Tate DF, Akbudak E, Lane EM, Heaps JM, Bolzenius JD, Baker LM, Cagle LM, Paul RH (2016) Neuromarkers of the common angiotensinogen polymorphism in healthy older adults: a comprehensive assessment of white matter integrity and cognition. Behav Brain Res 296:85-93. https://doi.org/10.1016/j.bbr.2015.08.028

37. Hajjar I, Kritchevsky S, Newman AB, Li R, Yaffe K, Simonsick EM, Lipsitz LA (2010) Renin angiotensin system gene polymorphisms modify angiotensin-converting enzyme inhibitors' effect on cognitive function: the health, aging and body composition study. J Am Geriatr Soc 58:1035-1042. https://doi.org/10.1111/j. 1532-5415.2010.02860.xs

38. Jiang T, Xue LJ, Yang Y, Wang QG, Xue X, Ou Z, Gao Q, Shi JQ, Wu L, Zhang YD (2018) AVE0991, a nonpeptide analogue of Ang-(1-7), attenuates aging-related neuroinflammation. Aging 10:645-657. https://doi.org/10.18632/aging.101419
39. Evans CE, Miners JS, Piva G, Willis CL, Heard DM, Kidd EJ, Good MA, Kehoe PG (2020) ACE2 activation protects against cognitive decline and reduces amyloid pathology in the Tg2576 mouse model of Alzheimer's disease. Acta Neuropathol 139:485502. https://doi.org/10.1007/s00401-019-02098-6

40. Goldstein B, Speth RC, Trivedi M (2016) Renin-angiotensin system gene expression and neurodegenerative diseases. J Renin Angiotensin Aldosterone Syst 17:1470320316666750. https://doi. org/10.1177/1470320316666750

41. Rocha NP, Scalzo PL, Barbosa IG, de Campos-Carli SM, Tavares LD, de Souza MS, Christo PP, Reis HJ, Simões E, Silva AC, Teixeira AL (2016) Peripheral levels of angiotensins are associated with depressive symptoms in Parkinson's disease. J Neurol Sci 368:235-239. https://doi.org/10.1016/j.jns.2016.07.031

42. Jiang T, Tan L, Gao Q, Lu H, Zhu XC, Zhou JS, Zhang YD (2016) Plasma angiotensin-(1-7) is a potential biomarker for Alzheimer's disease. Curr Neurovasc Res 13:96-99. https://doi.org/10.2174/ 1567202613666160224124739

43. Ribeiro VT, Cordeiro TME, Filha RDS, Perez LG, Caramelli P, Teixeira AL, de Souza LC, Simões E, Silva AC (2021) Circulating angiotensin-(1-7) Is reduced in Alzheimer's disease patients and correlates with white matter abnormalities: results from a pilot study. Front Neurosci 15:636754. https://doi.org/10.3389/fnins. 2021.636754

44. Kehoe PG, Wong S, Al Mulhim N, Palmer LE, Miners JS (2016) Angiotensin-converting enzyme 2 is reduced in Alzheimer's disease in association with increasing amyloid- $\beta$ and tau pathology. Alzheimers Res Ther 8:50. https://doi.org/10.1186/ s13195-016-0217-7

45. Ding Q, Shults NV, Gychka SG, Harris BT, Suzuki YJ (2021) Protein expression of angiotensin-converting enzyme 2 (ACE2) is upregulated in brains with Alzheimer's disease. Int J Mol Sci 22:1687. https://doi.org/10.3390/ijms22041687

46. Chen R, Wang K, Yu J, Howard D, French L, Chen Z, Wen C, Xu Z (2021) The spatial and cell-type distribution of SARS-CoV-2 receptor ACE2 in the human and mouse brains. Front Neurol 11:573095. https://doi.org/10.3389/fneur.2020.573095

47. Merello M, Bhatia KP, Obeso JA (2021) SARS-CoV-2 and the risk of Parkinson's disease: facts and fantasy. Lancet Neurol 20:94-95. https://doi.org/10.1016/S1474-4422(20)30442-7

Publisher's Note Springer Nature remains neutral with regard to jurisdictional claims in published maps and institutional affiliations. 